\title{
Estimativas de repetibilidade de híbridos diploides (AA) de bananeira
}

\author{
Lauro Saraiva Lessa(1), Carlos Alberto da Silva Ledo(2), Edson Perito Amorim ${ }^{(2)}$ e Sebastião de Oliveira e Silva(3) \\ (1)Embrapa Acre, BR 364, Km 14, Caixa Postal 321, CEP 69900-970 Rio Branco, AC, Brasil. E-mail: lauro.lessa@embrapa.br (2)Embrapa \\ Mandioca e Fruticultura, Rua da Embrapa s/nº, Bairro Chapadinha, Caixa Postal 007, CEP 44380-000 Cruz das Almas, BA, Brasil. \\ E-mail: carlos.ledo@embrapa.br, edson.amorim@embrapa.br ${ }^{(3)}$ Universidade Federal do Recôncavo da Bahia, Rua Rui Barbosa, no 710, \\ CEP 44 380-000 Cruz das Almas, BA, Brasil. E-mail: ssilva3000@gmail.com
}

Resumo - O objetivo deste trabalho foi estimar os coeficientes de repetibilidade em híbridos diploides de bananeira e predizer o número de medições necessárias para as principais características quantitativas. Os híbridos avaliados foram 042079-06, TH03-01, 089087-01, 003023-03, 013018-01, 001016-01, 086094-20, 013004-06 e 091079-03. Em três ciclos, mediram-se doze características agronômicas. Para a estimativa dos coeficientes de repetibilidade foram utilizadas as análises de variância, de componentes principais a partir das matrizes de variância e covariância fenotípica, de correlação e análise estrutural. Determinou-se para cada característica o número mínimo de medições, para predizer o valor real dos híbridos. Observou-se variabilidade genética entre os genótipos. As estimativas de repetibilidade foram elevadas, o que mostra a regularidade dos acessos. Para predizer o valor real dos caracteres de produção são necessárias de uma a cinco medições. Os métodos baseados em análise multivariada de componentes principais são os mais eficientes para estimar os coeficientes de repetibilidade.

Termos para indexação: Musa acuminata, análise multivariada, melhoramento genético, número de medições.

\section{Repeatability estimates of hybrid diploids (AA) of banana}

\begin{abstract}
The objective of this work was to estimate the coefficients of repeatability in diploid banana hybrids, and predict the number of required measurements for main quantitative traits. The evaluated hybrids were: 042079-06, TH03-01, 089087-01, 003023-03, 013018-01, 001016-01, 086094-20, 013004-06, and 091079-03. Twelve agronomic traits were measured in three cycles. For the repeatability coefficient estimate, the following analyses were performed: analysis of variance, principal components from the matrix of phenotypic variance and covariance analysis, and the correlation and structural analyses. For each trait, the minimum number of measurements to predict the actual value of the hybrids was determined. Genetic variability was observed among genotypes. Repeatability estimates were high, showing the regularity of accessions. One to five measurements are needed to predict the actual value of production characters. Methods based on principal component analysis are more efficient to estimate the coefficient of repeatability.
\end{abstract}

Index terms: Musa acuminata, multivariate analysis, breeding, number of measurements.

\section{Introdução}

Em mais de 80 países (Silva et al., 2002), a cultura da bananeira assume importância social e econômica e no Brasil, é a segunda maior atividade frutícola. A falta de cultivares resistentes às principais pragas e doenças, adaptadas aos diversos ecossistemas produtivos, comprovadamente superiores aos atuais genótipos em uso e que sejam aceitas pelos consumidores constituem-se nos principais fatores limitantes para a bananicultura nacional (Donato et al., 2006).

Uma das estratégias para superar essas limitações consiste no desenvolvimento de novas cultivares, oriundas dos programas de melhoramento genético de banana. Esses novos genótipos podem ser tanto triploides quanto tetraploides, produto do cruzamento entre cultivares comerciais (tri e tetraploides) e diploides melhorados ou selvagens (Silva et al., 2011; Amorim et al., 2013).

A variabilidade genética da bananeira que é importante para os programas de melhoramento localiza-se nos acessos diploides (Silva et al., 2002), que se constituem como fontes de alelos de interesse para o melhorista. Assim, um maior conhecimento quanto à variabilidade desses acessos e a estabilidade de suas características são informações imprescindíveis para selecionar possíveis parentais em programas de melhoramento.

Durante o processo de seleção, a certeza da superioridade genética do indivíduo é essencial, 
assim, são necessárias medições repetidas de um mesmo indivíduo ao longo do tempo (Lopes et al., 2001). Desta forma, a estimação dos coeficientes de repetibilidade é ferramenta relevante, pois fornece uma aproximação do valor máximo que a herdabilidade de uma característica, no sentido amplo, pode atingir (Cruz et al., 2004).

A estimação do coeficiente de repetibilidade de características de interesse vem sendo estudada por diversos autores, sobre várias culturas, como pupunheira (Farias Neto et al., 2002; Padilha et al., 2003), bacabi (Oliveira \& Moura, 2010), macaúba (Manfio et al., 2011), aceroleira (Lopes et al., 2001), goiabeira (Degenhardt et al., 2002), araçá e pitangeira (Danner et al., 2010), pessegueiro (Bruna et al., 2012) e laranjeira-doce (Negreiros et al., 2008, 2014).

Estudos de estimação do coeficiente de repetibilidade, em diploides de bananeira, podem precisar o número de medidas necessárias para se estimar o valor real do indivíduo, isto é, a soma dos efeitos permanentes genético e de meio, o que pode otimizar o tempo de avaliação de características de interesse em campo, reduzir gastos com insumos e subsidiar o melhorista com informações completas e precisas a respeito dos acessos, a custos menores.

O coeficiente de repetibilidade varia de 0 a 1 , em que $\mathrm{r}=1$ é o máximo verificado, quando a característica se manifesta com alta frequência. Portanto, valores altos para estimação da repetibilidade de uma dada característica são indicativos de que é possível predizer o valor real do indivíduo, com um número relativamente pequeno de avaliações (Farias Neto et al., 2002).

O objetivo deste trabalho foi estimar os coeficientes de repetibilidade em híbridos diploides de bananeira e predizer o número de medições necessárias para as principais características quantitativas.

\section{Material e Métodos}

O experimento foi realizado no Campo Experimental da Embrapa Mandioca e Fruticultura, em Cruz das Almas, BA, entre julho de 2005 e novembro de 2008. O município está situado a $12^{\circ} 40^{\prime} 19^{\prime \prime} \mathrm{S}, 39^{\circ} 06^{\prime} 22^{\prime \prime} \mathrm{W}$, a $220 \mathrm{~m}$ de altitude. O clima é tropical, quente e úmido, Aw a Am, segundo a classificação de Köppen, com temperatura média anual de $24,5^{\circ} \mathrm{C}$, umidade relativa de $80 \%$ e precipitação pluvial média de $1.249,7 \mathrm{~mm}$ anuais (Agritempo, 2009).

O solo da área experimental foi classificado como Latossolo Amarelo distrocoeso típico, bem drenado, profundo, de textura média e teores médios de argila (Rodrigues et al., 2009), com os seguintes atributos químicos na camada de $0-20 \mathrm{~cm}: \mathrm{pH}, 5,7$; $\mathrm{P}, 4,0 \mathrm{mg} \mathrm{dm}^{-3}$; K, 0,4 $\mathrm{cmol}_{\mathrm{c}} \mathrm{dm}^{-3}$; Ca, 2,4 $\mathrm{cmol}_{\mathrm{c}} \mathrm{dm}^{-3}$; $\mathrm{Mg}, \quad 1,0 \quad \mathrm{cmol}_{\mathrm{c}} \quad \mathrm{dm}^{-3} ; \quad \mathrm{Al}, \quad 0,2 \quad \mathrm{cmol}_{\mathrm{c}} \quad \mathrm{dm}^{-3}$; $\mathrm{Na}, 0,1 \mathrm{cmol}_{\mathrm{c}} \mathrm{dm}^{-3} ; \mathrm{Al}+\mathrm{H}, 2,86 \mathrm{cmol}_{\mathrm{c}} \mathrm{dm}^{-3} ; \mathrm{V}, 58 \%$; e $\mathrm{MO}, 9,72 \mathrm{~g} \mathrm{dm}^{-3}$.

Os híbridos diploides avaliados foram 042079-06, TH03-01, 089087-01, 003023-03, 013018-01, 001016-01, 086094-20, 013004-06 e 091079-03 (Tabela 1). Os híbridos, oriundos de uma população melhorada, foram escolhidos de forma aleatória. O material de plantio constituiu-se de mudas do tipo 'chifre', com aproximadamente quatro meses de idade, retiradas do Banco Ativo de Germoplasma de Bananeira da Embrapa Mandioca e Fruticultura. O plantio foi conduzido com irrigação, tendo-se utilizado o sistema de microaspersão, conforme recomendações de Coelho et al. (2006). Os tratos culturais utilizados foram os recomendados para a cultura da bananeira (Silva et al., 2002), e as adubações periódicas foram baseadas na análise de solo.

Avaliaram-se, em três ciclos de produção, a altura das plantas (m); o diâmetro do pseudocaule $(\mathrm{cm})$; o número de folhas na floração e na colheita; a presença de pólen, medida por meio de escala de notas em que 1 é ausência de pólen, 2 indica pequena quantidade de pólen, 3 representa média quantidade de pólen, e

Tabela 1. Códigos dos híbridos diploides (AA) de bananeira e seus respectivos parentais.

\begin{tabular}{ll}
\hline Híbridos $^{(1)}$ & \multicolumn{1}{c}{ Parentais } \\
\hline $042079-06$ & M53 x 028003 (Tuu Gia x Calcutta) \\
TH03-01 & Terrinha x Calcutta \\
$003023-03$ & Calcutta (Musa acuminata spp. burmannica) x cv. sem nome \\
$013018-01$ & Malaccensis FHIA x Sinwobogi \\
$001016-01$ & Borneo x Guyod \\
$086094-20$ & 003037-02 (Calcutta x Galeo) x SH32-63 \\
$013004-06$ & Malaccensis x Madang (Musa acuminata spp. banksii) \\
$091079-03$ & 001016-01 (Borneo x Guyod)x 028003 (Tuu Gia x Calcutta) \\
$089087-01$ & $\begin{array}{l}\text { 013018-01 (Malaccensis FHIA x Sinwobogi) x 003038-01 } \\
\text { (Calcutta x Heva) }\end{array}$ \\
\hline${ }^{(1)}$ Os primeiros números referem-se ao genitor feminino, os três seguintes \\
ao genitor masculino, e os dois últimos ao número da seleção.
\end{tabular}


4 corresponde à abundância de pólen; o período de formação de cacho (dias); a massa de cacho $(\mathrm{kg})$; o comprimento $(\mathrm{cm})$ e o diâmetro $(\mathrm{mm})$ do engaço; o número de pencas; o número de frutos; e a massa média de fruto (g). Utilizou-se o delineamento experimental de blocos ao acaso, com quatro repetições. Os dados foram submetidos à análise de variância conjunta, tendo-se utilizado as médias dos genótipos em cada ciclo de avaliação (Banzatto \& Kronka, 2006).

Foram utilizados quatro métodos para estimar os coeficientes de repetibilidade nos híbridos diploides (Tabela 2), descritos a seguir. O primeiro utilizou a análise de variância, em que o efeito temporário do ambiente é removido do erro, e os valores médios ordenados segundo o teste de agrupamento de Scott-Knott, a 5\% de probabilidade (Cruz et al., 2004). O segundo e o terceiro foram baseados na análise dos componentes principais: um a partir da matriz de variâncias e covariâncias fenotípicas (CPCOV); e o outro a partir da matriz de correlação (CPCOR), segundo o método de Abeywardena (1972) e Rutledge (1974). O quarto método utilizou a análise estrutural, a partir do autovalor teórico da matriz de correlação ou correlação média (AECOR), conforme Mansour et al. (1981).

O modelo estatístico utilizado para a análise de variância foi $Y_{i j}=\mu+g_{i}+a_{j}+\varepsilon_{i j}$, em que: $Y_{i j}$ é o caráter do i-ésimo genótipo, no j-ésimo ano de medição; $\mu$ é a média geral; $g_{i}$ é o efeito aleatório do i-ésimo genótipo, sob influência do ambiente permanente ( $\mathrm{i}=1,2, \ldots, 9$ genótipo); $\mathrm{a}_{\mathrm{j}}$ é o efeito da j-ésima mediação $\left(\mathrm{j}=1,2,3\right.$ ano); e $\varepsilon_{\mathrm{ij}}$ é o erro experimental associado ao caráter.

Tabela 2. Método de estimação do coeficiente de repetibilidade (r) e seus respectivos estimadores.

\begin{tabular}{|c|c|}
\hline Método de estimação & Estimador $^{(1)}$ \\
\hline $\begin{array}{l}\text { Análise de variância em que o efeito temporário do } \\
\text { ambiente é removido do erro }\end{array}$ & $\hat{\sigma}_{z}^{2} / \hat{\sigma}_{y}^{2}$ \\
\hline $\begin{array}{l}\text { Componentes principais obtidos da matriz de variância } \\
\text { e covariância fenotípica }\end{array}$ & $\hat{\lambda}_{1}-\hat{\sigma}_{y}^{2} / \hat{\sigma}_{y}^{2}(\eta-1)$ \\
\hline $\begin{array}{l}\text { Componentes principais obtidos da matriz de correlação } \\
\text { (CPCOR) }\end{array}$ & $\hat{\lambda}_{1}-1 / \eta-1$ \\
\hline $\begin{array}{l}\text { Análise estrutural com base no autovalor teórico da } \\
\text { matriz de correlação }(\hat{\mathrm{R}}) \text { ou correlação média }\end{array}$ & $\left(\hat{\alpha}^{\prime} \hat{\mathrm{R}} \hat{\alpha}\right.$ \\
\hline \multicolumn{2}{|c|}{$\begin{array}{l}\text { (1) } \hat{\sigma}_{y}^{2}=\hat{\sigma}_{a}^{2}+\hat{\sigma}_{g}^{2} ; \hat{\sigma}_{y}^{2} \text { é a variância fenotípica; } \hat{\sigma}_{\mathrm{a}}^{2} \text { é a variância ambiental; } \hat{\sigma}_{\mathrm{g}}^{2} \text { é a } \\
\text { variância genotípica; } \hat{\lambda}_{\mathrm{i}} \text { é o autovalor da matriz de covariância }(\hat{\Gamma}) \text { ou da } \\
\text { matriz de correlação }(\hat{R}) \text { associado ao autovetor, cujos elementos têm o } \\
\text { mesmo sinal, com magnitudes semelhantes; } \hat{\alpha} \text { é o autovetor associado ao } \\
\text { maior autovalor de } \hat{R} ; \eta \text { é o número de medições. }\end{array}$} \\
\hline
\end{tabular}

Foram determinados, para cada característica, o número mínimo de medições necessárias para predizer o valor real dos indivíduos $\left(\eta_{\mathrm{o}}\right)$, com base em um coeficiente de determinação $\left(\mathrm{R}^{2}\right)$ preestabelecido $(80$, 85, 90, 95 e 99\%), conforme Cruz et al. (2004), dado por $\eta_{\mathrm{o}}=\mathrm{R}^{2}(1-\mathrm{r}) /\left(1-\mathrm{R}^{2}\right) \mathrm{r}$, em que $\mathrm{r}$ é o coeficiente de repetibilidade, obtido de acordo com um dos diferentes métodos utilizados.

O coeficiente de determinação genotípica $\left(\mathrm{R}^{2}\right)$, que representa a percentagem de certeza da predição do valor real dos indivíduos selecionados, com base em $\eta$ medições, foi obtido pela expressão $\mathrm{R}^{2}=(\eta \times \mathrm{r}) /[1+\mathrm{r}(\eta-\mathrm{r})]$, em que: $\eta$ é o número de medições; e r é o coeficiente de repetibilidade, obtido de acordo com um dos diferentes métodos utilizados. A análise estatística dos dados foi realizada com auxílio do programa Genes (Cruz, 2006).

\section{Resultados e Discussão}

Houve variabilidade genética entre os híbridos diploides (AA) de bananeira para a maioria dos caracteres avaliados (Tabela 3). Os coeficientes de variação, observados no presente trabalho, foram semelhantes aos obtidos por Silva et al. (2002), Lima et al. (2005), Donato et al. (2006), Silva et al. (2006), Oliveira et al. (2008).

Quanto à altura de plantas, característica decisiva na escolha do espaçamento (Silva et al., 2002), o híbrido 013004-06 apresentou a maior média, superior à dos demais. Nas características diâmetro do pseudocaule e número de folhas na floração, não se observaram diferenças significativas entre os híbridos (Tabela 4). Segundo Silva et al. (2011), esses caracteres são de grande importância para a cultura, pois o diâmetro é relacionado à capacidade de sustentação do cacho, à suscetibilidade ao tombamento e, também, ao número de folhas e ao desenvolvimento do cacho.

Para a característica presença de pólen, os híbridos 089087-01, 013018-01, 001016-01, 086094-20 e 013004-06 formaram o grupo dos genótipos superiores (Tabela 4). No período de formação do cacho, o híbrido 091079-03 apresentou ciclo mais prolongado do que os demais genótipos. Para Lessa et al. (2009), esta característica é bastante influenciada pelo ambiente, pois depende das condições climáticas da região.

Quanto ao número de folhas na colheita, não se observou diferença significativa entre os híbridos 
diploides (AA) de bananeira (Tabela 4). $\mathrm{Na}$ massa de cacho, destacaram-se os híbridos 042079-06 e 013018-01, que foram superiores aos demais. Em comprimento do engaço, observou-se que o híbrido 086094-20 apresentou a maior média. Segundo Silva et al. (1999), há uma ampla variabilidade entre genótipos com relação a esta característica, que pode ser de grande importância na caracterização de novos materiais. Porém, para diâmetro de engaço, não se observou diferença significativa entre os híbridos estudados.

$\mathrm{Na}$ característica número de pencas e de frutos, observou-se a formação de cinco grupos, tendo sido o híbrido 001016-01 superior aos demais (Tabela 4). Segundo alguns autores (Silva et al., 2006; Oliveira et al., 2008), estes caracteres são de interesse para o produtor, uma vez que a penca constitui-se como unidade comercial. Quanto à massa média do fruto, obteve-se a formação de dois grupos, em que os híbridos 04079-06, TH03-01, 003023-03 e 013018-01 apresentaram as maiores massas.

Em relação aos ciclos, observou-se tendência de estabilização para a maioria dos caracteres, a partir do segundo ciclo de avaliação (Tabela 4). Esses dados estão de acordo com o observado por Silva et al. (2002).

Com exceção dos caracteres número de folhas na floração e na colheita, além do diâmetro de engaço, houve grande concordância das magnitudes dos coeficientes de repetibilidade obtidos pelos diferentes métodos, o que lhes confere maior confiabilidade dos resultados observados.

Tabela 3. Quadro de análise de variância de nove híbridos diploides (AA) de bananeira, avaliados em três ciclos, em Cruz das Almas, BA.

\begin{tabular}{|c|c|c|c|c|c|c|c|c|c|c|c|c|c|}
\hline \multirow{2}{*}{$\begin{array}{l}\text { Fonte de } \\
\text { Variação }\end{array}$} & \multirow[t]{2}{*}{ GL } & \multicolumn{12}{|c|}{ Quadrado médio } \\
\hline & & $\operatorname{ALT}(\mathrm{m})$ & $\mathrm{DPC}(\mathrm{cm})$ & NFF & $\mathrm{PPO}$ & CEC (dias) & NFC & $\mathrm{PCH}$ & $\mathrm{CME}(\mathrm{cm})$ & DME $(\mathrm{mm})$ & NPE & NFR & PMF (g) \\
\hline Ciclos & 2 & $1,19 * *$ & $4,65 * *$ & $21,35 * *$ & $0,45^{\mathrm{ns}}$ & $63,05^{\mathrm{ns}}$ & $4,62 * *$ & $3,57 * *$ & $47,68^{*}$ & $44,59^{* *}$ & $2,50 * *$ & $1360,05^{* *}$ & $521,20 * *$ \\
\hline Híbridos & 8 & $0,34 * *$ & $2,75 * *$ & $1,24^{\mathrm{ns}}$ & $1,81 * *$ & $815,26^{* *}$ & $1,26^{\mathrm{ns}}$ & $1,14 * *$ & $175,74 * *$ & $8,13^{\mathrm{ns}}$ & $6,30 * *$ & $2358,72 * *$ & $282,95 * *$ \\
\hline Resíduo & 16 & 0,01 & 0,50 & 0,51 & 0,13 & 46,51 & 0,74 & 0,22 & 8,32 & 6,30 & 0,10 & 80,54 & 25,39 \\
\hline Média & & 2,41 & 14,48 & 9,04 & 2,49 & 149,53 & 2,43 & 3,61 & 35,27 & 38,25 & 7,08 & 114,73 & 29,57 \\
\hline CV $(\%)$ & & 5,56 & 4,89 & 7,92 & 14,70 & 4,56 & 35,42 & 13,12 & 8,18 & 6,57 & 4,53 & 7,82 & 17,04 \\
\hline
\end{tabular}

${ }^{n}$ Não significativo. * e **Significativo a 5 e $1 \%$ de probabilidade, respectivamente. ALT, altura de planta; DPC, diâmetro do pseudocaule; NFF, número de folhas na floração; PPO, presença de pólen; CEC, dias da emissão do cacho à colheita; NFC, número de folhas na colheita; PCH, massa de cacho; CME, comprimento de engaço; DME, diâmetro de engaço; NPE, número de pencas; NFR, número de frutos; PMF, massa de fruto.

Tabela 4. Médias das características agronômicas e dos ciclos de nove híbridos diploides (AA) de bananeira, em Cruz das Almas, BA ${ }^{(1)}$.

\begin{tabular}{|c|c|c|c|c|c|c|c|c|c|c|c|c|}
\hline Híbrido/ciclo & ALT (m) & $\mathrm{DPC}(\mathrm{cm})$ & NFF & $\mathrm{PPO}$ & CEC (dias) & NFC & $\mathrm{PCH}$ & $\mathrm{CME}(\mathrm{cm})$ & $\operatorname{DME}(\mathrm{mm})$ & $\mathrm{NPE}$ & NFR & PMF (g) \\
\hline $042079-06$ & $2,53 b$ & 15,90 & 9,06 & $1,67 \mathrm{~b}$ & $158,13 b$ & 1,87 & $4,47 a$ & $28,75 d$ & 40,24 & $5,70 \mathrm{e}$ & $97,26 \mathrm{~d}$ & $44,04 a$ \\
\hline TH03-01 & $2,14 \mathrm{c}$ & 14,03 & 9,90 & $1,97 \mathrm{~b}$ & $157,72 b$ & 1,50 & $3,55 b$ & $24,82 \mathrm{~d}$ & 41,19 & $5,90 \mathrm{e}$ & $80,80 \mathrm{e}$ & $40,58 \mathrm{a}$ \\
\hline 089087-01 & $2,04 \mathrm{c}$ & 12,58 & 9,38 & $3,28 \mathrm{a}$ & $141,15 \mathrm{c}$ & 2,67 & $2,95 b$ & $37,33 \mathrm{c}$ & 37,82 & $6,66 \mathrm{~d}$ & $105,22 \mathrm{~d}$ & $24,37 \mathrm{~b}$ \\
\hline 003023-03 & $2,65 b$ & 15,16 & 8,50 & $1,21 \mathrm{~b}$ & $130,75 \mathrm{c}$ & 2,66 & $3,34 \mathrm{~b}$ & $27,85 \mathrm{~d}$ & 37,77 & $5,94 \mathrm{e}$ & $80,47 \mathrm{e}$ & $36,44 a$ \\
\hline 013018-01 & $2,53 b$ & 14,48 & 10,04 & $3,30 \mathrm{a}$ & $142,02 \mathrm{c}$ & 3,40 & $4,71 \mathrm{a}$ & $41,16 b$ & 36,78 & $6,71 d$ & $120,30 \mathrm{c}$ & $35,70 \mathrm{a}$ \\
\hline 001016-01 & $2,64 b$ & 13,87 & 8,78 & $3,08 \mathrm{a}$ & $149,09 b$ & 3,09 & $3,71 \mathrm{~b}$ & $31,73 \mathrm{~d}$ & 37,13 & $9,68 \mathrm{a}$ & $159,76 \mathrm{a}$ & $20,59 \mathrm{~b}$ \\
\hline 086094-20 & $1,86 \mathrm{c}$ & 15,19 & 8,85 & $2,81 \mathrm{a}$ & $147,37 \mathrm{~b}$ & 1,67 & $3,35 b$ & $47,94 a$ & 39,50 & $6,26 \mathrm{~d}$ & $105,84 \mathrm{~d}$ & $25,81 \mathrm{~b}$ \\
\hline 013004-06 & $2,91 \mathrm{a}$ & 14,70 & 8,02 & $3,08 \mathrm{a}$ & $133,93 \mathrm{c}$ & 2,74 & $3,49 b$ & $35,55 \mathrm{c}$ & 36,64 & $9,06 \mathrm{~b}$ & $142,65 b$ & $21,23 \mathrm{~b}$ \\
\hline 091079-03 & $2,41 \mathrm{c}$ & 14,37 & 8,86 & $2,07 \mathrm{~b}$ & $185,66 \mathrm{a}$ & 2,25 & $2,90 \mathrm{~b}$ & $42,32 b$ & 37,21 & $7,83 \mathrm{c}$ & $140,26 \mathrm{~b}$ & $17,41 \mathrm{~b}$ \\
\hline Ciclo 1 & $1,99 b$ & $13,69 b$ & $10,80 \mathrm{a}$ & 2,65 & 148,25 & $1,79 \mathrm{~b}$ & $4,32 \mathrm{a}$ & $32,99 \mathrm{~b}$ & $40,73 a$ & $6,64 b$ & $105,98 \mathrm{~b}$ & $37,87 \mathrm{a}$ \\
\hline Ciclo 2 & $2,60 \mathrm{a}$ & $14,65 \mathrm{a}$ & $8,39 \mathrm{~b}$ & 2,60 & 147,78 & $3,21 \mathrm{a}$ & $3,38 \mathrm{~b}$ & $37,59 \mathrm{a}$ & $37,63 b$ & $7,67 \mathrm{a}$ & $128,78 \mathrm{a}$ & $22,93 \mathrm{~b}$ \\
\hline Ciclo 3 & $2,64 \mathrm{a}$ & $15,10 \mathrm{a}$ & $7,94 \mathrm{~b}$ & 2,24 & 152,58 & $2,28 \mathrm{ab}$ & $3,12 b$ & $35,24 \mathrm{ab}$ & $36,41 \mathrm{~b}$ & $6,93 b$ & $109,42 b$ & $27,92 \mathrm{~b}$ \\
\hline
\end{tabular}

(1)Médias seguidas por letras iguais, nas colunas, para os valores médios dos diploides, pertencem ao mesmo grupo, pelo teste de Scott-Knott. Médias seguidas por letras iguais, para os valores médios dos ciclos, não diferem entre si, pelo teste de Tukey, a 5\% de probabilidade. ALT, altura de plantas; DPC, diâmetro do pseudocaule; NFF, número de folhas na floração; PPO, presença de pólen; CEC, dias da emissão do cacho à colheita; NFC, número de folhas na colheita; PCH, massa de cacho; CME, comprimento de engaço; DME, diâmetro de engaço; NPE, número de pencas; NFR, número de frutos; PMF, massa de fruto. 
Observaram-se, para a altura de plantas, coeficientes de repetibilidade entre 0,8578 e 0,9434 , pela análise de variância e CPCOV, respectivamente. Nesta característica, os coeficientes de determinação foram superiores a $90 \%$, em todos os métodos estudados. Coeficientes de determinação $\left(\mathrm{R}^{2}\right)$ superiores a $80 \%$ indicam boa confiabilidade das informações (Oliveira \& Moura, 2010). Tendência semelhante foi observada quanto à característica diâmetro do pseudocaule (Tabela 5).

$\mathrm{Na}$ característica número de folhas na floração, as estimativas de coeficientes de repetibilidade estiveram

Tabela 5. Estimativas do coeficiente de repetibilidade (r) e seus coeficientes de determinação $\left(R^{2}, \%\right)$, observados em 12 características agronômicas de híbridos diploides (AA), em três ciclos de avaliação, em Cruz das Almas, BA.

\begin{tabular}{|c|c|c|c|c|c|}
\hline Característica $^{(1)}$ & & Anova & CPCOV & CPCOR & AECOR \\
\hline \multirow[t]{2}{*}{ ALT } & $\mathrm{r}$ & 0,8578 & 0,9434 & 0,9153 & 0,9148 \\
\hline & $\mathrm{R}^{2}$ & 94,76 & 98,03 & 97,00 & 96,99 \\
\hline \multirow[t]{2}{*}{ DPC } & $\mathrm{r}$ & 0,6003 & 0,8198 & 0,6888 & 0,6842 \\
\hline & $\mathrm{R}^{2}$ & 81,83 & 93,17 & 86,90 & 86,66 \\
\hline \multirow[t]{2}{*}{ NFF } & $\mathrm{r}$ & 0,3203 & 0,5308 & 0,4000 & 0,3860 \\
\hline & $\mathrm{R}^{2}$ & 58,56 & 77,23 & 66,66 & 65,35 \\
\hline \multirow[t]{2}{*}{ PPO } & $\mathrm{r}$ & 0,8071 & 0,8228 & 0,8131 & 0,8127 \\
\hline & $\mathrm{R}^{2}$ & 92,62 & 93,30 & 92,88 & 92,86 \\
\hline \multirow[t]{2}{*}{ CEC } & $\mathrm{r}$ & 0,8464 & 0,8468 & 0,8496 & 0,8484 \\
\hline & $\mathrm{R}^{2}$ & 94,29 & 94,31 & 94,42 & 94,37 \\
\hline \multirow[t]{2}{*}{ NFC } & $\mathrm{r}$ & 0,1879 & 0,3037 & 0,2883 & 0,1849 \\
\hline & $\mathrm{R}^{2}$ & 40,96 & 56,67 & 54,85 & 40,50 \\
\hline \multirow[t]{2}{*}{$\mathrm{PCH}$} & $\mathrm{r}$ & 0,5785 & 0,7861 & 0,6477 & 0,6416 \\
\hline & $\mathrm{R}^{2}$ & 80,45 & 91,68 & 84,65 & 84,30 \\
\hline \multirow[t]{2}{*}{ CME } & $\mathrm{r}$ & 0,8701 & 0,8885 & 0,8840 & 0,8838 \\
\hline & $\mathrm{R}^{2}$ & 95,25 & 95,98 & 95,81 & 95,79 \\
\hline \multirow[t]{2}{*}{ DME } & $\mathrm{r}$ & 0,0883 & 0,2115 & 0,2344 & 0,1235 \\
\hline & $\mathrm{R}^{2}$ & 22,52 & 44,58 & 47,88 & 29,71 \\
\hline \multirow[t]{2}{*}{ NPE } & $\mathrm{r}$ & 0,9523 & 0,9555 & 0,9556 & 0,9554 \\
\hline & $\mathrm{R}^{2}$ & 98,35 & 98,47 & 98,47 & 98,46 \\
\hline \multirow[t]{2}{*}{ NFR } & $\mathrm{r}$ & 0,9041 & 0,9060 & 0,9071 & 0,9071 \\
\hline & $\mathrm{R}^{2}$ & 96,58 & 96,65 & 96,69 & 96,69 \\
\hline \multirow[t]{2}{*}{ PMF } & $\mathrm{r}$ & 0,7718 & 0,8784 & 0,8796 & 0,8789 \\
\hline & $\mathrm{R}^{2}$ & 91,02 & 95,58 & 95,63 & 95,60 \\
\hline
\end{tabular}

(1)ALT, altura de plantas; DPC, diâmetro do pseudocaule; NFF, número de folhas na floração; PPO, presença de pólen; CEC, dias da emissão do cacho à colheita; NFC, número de folhas na colheita; $\mathrm{PCH}$, massa de cacho; CME, comprimento de engaço; DME, diâmetro de engaço; NPE, número de pencas; NFR, número de frutos; PMF, massa de fruto. CPCOV, componentes principais obtidos da matriz de variâncias e covariâncias fenotípicas; CPCOR, componentes principais obtidos da matriz de correlação; AECOR, análise estrutural com base no autovalor teórico da matriz de correlação ou correlação média. abaixo daquelas consideradas aceitáveis para plantas perenes, conforme Bruna et al. (2012); com a análise de variância, obteve-se a menor estimativa, em comparação aos demais métodos. Resultados semelhantes foram observados para o número de folhas na colheita. Coeficientes de repetibilidade baixos podem estar relacionados à variação ambiental (Ferreira et al., 2005), o que acarreta menor regularidade da característica e necessidade de maior número de medições, para se chegar a um nível de acurácia satisfatório.

Quanto às características presença de pólen e período entre a emissão de cacho e a colheita, as estimativas de repetibilidade foram superiores a 0,80 , o que indica uma boa regularidade dos caracteres, com pouca influência ambiental (Tabela 5). Para Resende (2002), estimativas de $r \geq 0,60$ são consideradas altas e de maior confiabilidade.

A característica massa de cacho, de interesse no melhoramento de bananeira, apresentou estimativas de $r$ entre 0,57 (Anova) e 0,78 (CPCOV). Os coeficientes de determinação observados foram 80,45\% (Anova), 91,68\% (CPCOV), 84,65\% (CPCOR), 84,30\% (AECOR) (Tabela 5). Segundo Shimoya et al. (2002), valores acima de 0,50 são considerados aceitáveis, pois expressam coeficientes de determinação superiores a $80 \%$ e apresentam, portanto, boa regularidade da característica. A regularidade da produção é um fator importante para a seleção de híbridos diploides (AA) de bananeira, pois o genótipo selecionado pode passar essa característica a descendentes, quando cruzado com outros diploides ou triploides, em programas de melhoramento genético da cultura.

Quanto ao comprimento e diâmetro de engaço, verificou-se discordância entre as estimativas. No primeiro, as estimativas variaram entre $0,8701\left(\mathrm{R}^{2}=95,25 \%\right)$ e $0,8885\left(\mathrm{R}^{2}=95,98 \%\right)$, obtidas pela Anova e CPCOV, respectivamente. Em relação ao diâmetro, as estimativas de repetibilidade (r) ficaram abaixo de 0,25 , e o coeficiente de determinação $\left(R^{2}\right)$ foi menor que $50 \%$ (Tabela 5), o que indica pouca regularidade da característica e necessidade de mais medições para aumentar o nível de acurácia.

Quanto aos caracteres número de pencas e frutos por cacho, observaram-se estimativas de repetibilidade altas (Resende, 2002; Ferreira et al., 2005), com valores acima de 0,90. Os coeficientes de determinação foram superiores a $90 \%$ para ambas as características 
(Tabela 5), o que significa que elas apresentaram boa regularidade das medições e que isto permite reduzir as avaliações, se necessário, o que também foi observado quanto à caraterística massa de fruto (PMF). Segundo Vencovsky (1973), coeficientes de repetibilidade altos podem ser empregados como parâmetros para medir a capacidade de repetição da caraterística avaliada. Assim, pode-se sugerir que as características número de pencas, número de frutos e massa de fruto poderiam ser utilizadas como parâmetros desejáveis no melhoramento de diploides de bananeira, para aumentar a variabilidade entre acessos.

A variação das estimativas de $\mathrm{r}$, o alto valor apresentado pelos métodos multivariados, principalmente o de componentes principais baseado na matriz de variância e covariância (CPCOV), são indicativos de que houve regularidade na repetição do desempenho dos híbridos diploides (AA) de bananeira, ao longo das medições (Cruz et al., 2004). Segundo Negreiros et al. (2008), altos valores de r e R ${ }^{2}$ denotam o bom controle genético dessas expressões e que a variância ambiental foi relativamente baixa, em comparação à variância existente entre plantas. Bruna et al. (2012) sugerem o emprego das características com alto $\mathrm{r}$ e $\mathrm{R}^{2}$ como parâmetros, para medir a capacidade de repetição da expressão do caráter avaliado.

Ao se considerar o valor de $\mathrm{R}^{2}$ ideal, deve-se também considerar, além da confiabilidade das informações geradas com a análise dos dados, a disponibilidade de recursos e, também, que números exagerados de medidas poderiam inviabilizar as avaliações de experimentos de bananeira. Assim, são considerados aceitáveis $\mathrm{R}^{2}$ com $90 \%$ de certeza, indicativos de boa confiabilidade e boa acurácia dos dados, conforme relatam alguns autores (Degenhardt et al., 2002; Danner et al., 2010; Manfio et al., 2011; Matsuo et al., 2012).

Em comparação aos demais métodos, CPCOV e CPCOR apresentaram número de medições menor para todas as variáveis (Tabela 6), o que indica a eficiência destes métodos na predição do valor real das características agronômicas em híbridos diploides (AA) de bananeira, uma vez que se observou alternância de sinal nos elementos do primeiro autovetor. Segundo Abeywardena (1972), o coeficiente de repetibilidade é mais eficientemente estimado pelo método dos componentes principais, pois estes levam em consideração o caráter cíclico da cultura. Com o método baseado na Anova, ou seja, univariado, não é possível isolar o fator periodicidade e, ao incorporá-lo na estimativa, eleva-se o valor do erro experimental (Negreiros et al., 2014). Isso pode subestimar a estimativa de repetibilidade (Vasconcellos et al., 1985).

O número de medidas para a variável altura de plantas foi de 1,0, e o coeficiente de determinação foi de $90 \%$. No diâmetro do pseudocaule, houve aumento do número de medições necessárias de 2 a 4 medidas quanto à ALT e DPC, respectivamente, quando se considerou $90 \%$ de certeza. Em relação à característica número de folhas na floração, para os mesmos métodos, são necessárias de 8 a 13 medidas, para se ter um nível de certeza considerável.

Negreiros et al. (2008) relatam que altos valores de certeza mostram a acurácia das medições realizadas, com boa regularidade dos indivíduos de um ciclo para outro. Assim, pode-se inferir que quanto maior o número de medidas necessárias, maior o efeito do ambiente sobre a variável. Esse mesmo efeito foi observado nas características número de folhas na colheita e diâmetro de engaço, com número de medições superiores a 20 e 30, respectivamente, nos quatro métodos estudados, com $90 \%$ de certeza (Tabela 6).

Para as características presença de pólen e período entre a emissão e a colheita do cacho obteve-se número necessário de medições de aproximadamente duas, com os métodos de CPCOV e CPCOR e 90\% de confiabilidade, resultante da elevada estimativa do coeficiente de repetibilidade. Segundo Matsuo et al. (2012), quando o coeficiente de repetibilidade é elevado, o número de medições torna-se relativamente pequeno.

Quanto aos números de pencas e de frutos, pôdese observar número de medições sugeridas inferior a um (01), em todos os métodos, com $90 \%$ de confiabilidade. Em relação à massa de cacho, com o mesmo nível de confiabilidade, observou-se número de medições entre 2,44 e 4,89, respectivamente para CPCOV e CPCOR. Em relação à massa de frutos, valores de aproximadamente duas medidas podem expressar o valor real dos genótipos, quando se utilizam os mesmos métodos, com base nos componentes principais. 
Tabela 6. Número de medições necessárias para a predição do valor real dos híbridos diploides (AA) de bananeira, quanto a 12 características, por quatro diferentes métodos, e coeficiente de determinação $\left(\mathrm{R}^{2}, \%\right)$ de 80, 85, 90, 95 e 99\%, em três ciclos de colheita, em Cruz das Almas, BA.

\begin{tabular}{|c|c|c|c|c|c|c|c|c|c|}
\hline $\mathrm{R}^{2}$ & Anova & CPCOV & CPCOR & AECOR & $\mathrm{R}^{2}$ & Anova & CPCOV & CPCOR & AECOR \\
\hline \multicolumn{6}{|c|}{ Altura de plantas (ALT) } & \multicolumn{4}{|c|}{ Massa de cacho $(\mathrm{PCH})$} \\
\hline 80 & 0,66 & 0,24 & 0,37 & 0,37 & 80 & 2,91 & 1,08 & 2,17 & 2,23 \\
\hline 85 & 0,93 & 0,34 & 0,52 & 0,52 & 85 & 4,12 & 1,54 & 3,08 & 3,16 \\
\hline 90 & 1,49 & 0,54 & 0,83 & 0,83 & 90 & 6,55 & 2,44 & 4,89 & 5,02 \\
\hline 95 & 3,14 & 1,14 & 1,75 & 1,76 & 95 & 13,84 & 5,17 & 10,33 & 10,61 \\
\hline 99 & 16,40 & 5,94 & 9,15 & 9,21 & 99 & 72,14 & 26,94 & 53,83 & 55,30 \\
\hline \multicolumn{6}{|c|}{ Diâmetro do pseudocaule (DPC) } & \multicolumn{4}{|c|}{ Comprimento de engaço (CME) } \\
\hline 80 & 2,66 & 0,87 & 1,80 & 1,84 & 80 & 0,59 & 0,50 & 0,52 & 0,52 \\
\hline 85 & 3,77 & 1,24 & 2,56 & 2,61 & 85 & 0,84 & 0,71 & 0,74 & 0,74 \\
\hline 90 & 5,99 & 1,97 & 4,06 & 4,15 & 90 & 1,34 & 1,13 & 1,18 & 1,18 \\
\hline 95 & 12,65 & 4,17 & 8,58 & 8,77 & 95 & 2,83 & 2,38 & 2,49 & 2,49 \\
\hline 99 & 65,92 & 21,76 & 44,73 & 45,70 & 99 & 14,78 & 12,42 & 12,98 & 13,02 \\
\hline \multicolumn{6}{|c|}{ Número de folhas na floração (NFF) } & \multicolumn{4}{|c|}{ Diâmetro de engaço (DME) } \\
\hline 80 & 8,49 & 3,53 & 5,99 & 6,36 & 80 & 41,28 & 14,91 & 13,06 & 28,38 \\
\hline 85 & 12,02 & 5,00 & 8,49 & 9,01 & 85 & 58,48 & 21,13 & 18,50 & 40,21 \\
\hline 90 & 19,10 & 7,95 & 13,49 & 14,31 & 90 & 92,88 & 33,56 & 29,38 & 63,86 \\
\hline 95 & 40,32 & 16,79 & 28,49 & 30,2 & 95 & 196,08 & 70,85 & 62,04 & 134,83 \\
\hline 99 & 210,11 & 87,51 & 148,48 & 157,46 & 99 & $1.021,72$ & 369,18 & 323,27 & 702,54 \\
\hline \multicolumn{6}{|c|}{ Presença de pólen (PPO) } & \multicolumn{4}{|c|}{ Número de pencas (NPE) } \\
\hline 80 & 0,95 & 0,86 & 0,91 & 0,92 & 80 & 0,20 & 0,18 & 0,18 & 0,18 \\
\hline 85 & 1,35 & 1,22 & 1,30 & 1,30 & 85 & 0,28 & 0,26 & 0,26 & 0,26 \\
\hline 90 & 2,15 & 1,93 & 2,06 & 2,07 & 90 & 0,45 & 0,41 & 0,41 & 0,42 \\
\hline 95 & 4,54 & 4,09 & 4,36 & 4,37 & 95 & 0,95 & 0,88 & 0,88 & 0,88 \\
\hline 99 & 23,65 & 21,31 & 22,75 & 22,81 & 99 & 4,95 & 4,60 & 4,60 & 4,62 \\
\hline \multicolumn{6}{|c|}{ Dias da emissão do cacho à colheita (CEC) } & \multicolumn{4}{|c|}{ Número de frutos (NFR) } \\
\hline 80 & 0,72 & 0,72 & 0,70 & 0,71 & 80 & 0,42 & 0,41 & 0,41 & 0,41 \\
\hline 85 & 1,02 & 1,02 & 1,00 & 1,01 & 85 & 0,60 & 0,58 & 0,58 & 0,58 \\
\hline 90 & 1,63 & 1,62 & 1,59 & 1,60 & 90 & 0,95 & 0,93 & 0,92 & 0,92 \\
\hline 95 & 3,44 & 3,43 & 3,36 & 3,39 & 95 & 2,01 & 1,97 & 1,94 & 1,94 \\
\hline 99 & 17,97 & 17,90 & 17,52 & 17,68 & 99 & 10,50 & 10,27 & 10,13 & 10,14 \\
\hline \multicolumn{6}{|c|}{ Número de folhas na colheita (NFC) } & \multicolumn{4}{|c|}{ Massa de fruto (PMF) } \\
\hline 80 & 17,29 & 9,17 & 9,87 & 17,62 & 80 & 1,18 & 0,55 & 0,54 & 0,55 \\
\hline 85 & 24,49 & 12,99 & 13,99 & 24,97 & 85 & 1,67 & 0,78 & 0,77 & 0,78 \\
\hline 90 & 38,90 & 20,63 & 22,22 & 39,66 & 90 & 2,66 & 1,24 & 1,23 & 1,24 \\
\hline 95 & 82,14 & 43,56 & 46,91 & 83,73 & 95 & 5,61 & 2,63 & 2,60 & 2,61 \\
\hline 99 & 427,99 & 226,99 & 244,45 & 436,31 & 99 & 29,27 & 13,70 & 13,54 & 13,64 \\
\hline
\end{tabular}

\section{Conclusões}

1. Há concordância entre as magnitudes dos coeficientes de repetibilidade obtidos pelos diferentes métodos, com boa regularidade na predição do número de medições em híbridos diploides (AA) de bananeira.

2. São necessárias, aproximadamente, de 1 a 5 medições para a predição do valor real dos caracteres relacionados à produção (massa de cacho, número de pencas, número de frutos e massa de frutos), em híbridos diploides (AA) de bananeira.
3. Os métodos baseados em análise multivariada de componentes principais são mais eficientes para a estimação do coeficiente de repetibilidade.

\section{Agradecimentos}

Ao Conselho Nacional de Desenvolvimento Científico e Tecnológico (CNPq), pelo apoio financeiro; à Embrapa Mandioca e Fruticultura, pela concessão do material vegetal para estudo e pela logística de campo. 


\section{Referências}

ABEYWARDENA, V. An application of principal component analysis in genetics. Journal of Genetics, v.61, p.27-51, 1972. DOI: 10.1007/BF02984099.

AGRITEMPO. 2009. Disponível em: < http://www.agritempo.gov. br/agroclima/sumario $>$. Acesso em: 5 out. 2013.

AMORIM, E.P.; SANTOS-SEREJO, J.A. dos; AMORIM, V.B.O.; FERREIRA, C.F.; SILVA, S.O. Banana breeding at Embrapa Cassava and Fruits. Acta Horticulturae, v.986, p.171-176, 2013.

BANZATTO, D.A.; KRONKA, S. do N. Experimentação agrícola. 4.ed. Jaboticabal: Funep, 2006. 237p.

BRUNA, E.D.; MORETO, A.L.; DALBÓ, M.A. Uso do coeficiente de repetibilidade na seleção de clones de pessegueiro para o litoral sul de Santa Catariana. Revista Brasileira de Fruticultura, v.34, p.206-215, 2012. DOI: 10.1590/S0100-29452012000100028.

COELHO, E.F.; LEDO, C.A. da S.; SILVA, S. de O. e. Produtividade da bananeira 'Prata-Anã' e 'Grande Naine' no terceiro ciclo sob irrigação por microaspersão em tabuleiros costeiros da Bahia. Revista Brasileira de Fruticultura, v.28, p.435-438, 2006. DOI: 10.1590/S0100-29452006000300021.

CRUZ, C.D. Programa Genes: biometria. Viçosa: Ed. da UFV, 2006. 382p.

CRUZ, C.D.; REGAZZI, A.J.; CARNEIRO, P.C.S. Modelos biométricos aplicados ao melhoramento Genético. Viçosa: Ed. da UFV, 2004. v.1, 480p.

DANNER, M.A.; RASEIRA, M. do C.B.; SASSO, S.A.Z.; CITADIN, I.; SCARIOT, S. Repetibilidade de caracteres de fruto em araçazeiro e pitangueira. Ciência Rural, v.40, p.2086-2091, 2010. DOI: $10.1590 / \mathrm{S} 0103-84782010005000163$.

DEGENHARDT, J.; DUCROQUET, J.P.; REIS, M.S. dos; GUERRA, M.P.; NODARI, R.O. Efeito de anos e determinação do coeficiente de repetibilidade de características de frutos de goiabeira-serrana. Pesquisa Agropecuária Brasileira, v.37, p.1285-1293, 2002. DOI: 10.1590/S0100-204X2002000900012.

DONATO, S.L.R.; SILVA, S. de O. e; LUCCA FILHO, O.A.; LIMA, M.B.; DOMINGUES, H.; ALVES, J. da S. Correlações entre caracteres da planta e do cacho em bananeira (Musa spp.). Ciência e Agrotecnologia, v.30, p.21-30, 2006. DOI: 10.1590/ S1413-70542006000100003.

FARIAS NETO, J.T. de; YOKOMIZO, G.; BIANCHETTI, A. Coeficientes de repetibilidade genética de caracteres em pupunheiras. Revista Brasileira de Fruticultura, v.24, p.731-733, 2002. DOI: 10.1590/S0100-29452002000300042.

FERREIRA, A.; BARBOSA, M.H.P.; CRUZ, C.D.; HOFFMANN, H.P.; VIEIRA, M.A.S.; BASSINELLO, A.I.; SILVA, M.F. da. Repetibilidade e número de colheitas para seleção de clones de cana-de-açúcar. Pesquisa Agropecuária Brasileira, v.40, p.761-767, 2005. DOI: 10.1590/S0100-204X2005000800005.

LESSA, L.S.; LEDO, C.A. da S.; SILVA, S. de O. e; PEIXOTO, C.P. Avaliação agronômica em híbridos diploides (AA) de bananeira. Ciência e Agrotecnologia, v.33, p.1716-1721, 2009. DOI: $10.1590 / \mathrm{S} 1413-70542009000700003$.
LIMA, M.B.; SILVA, S. de O.; JESUS, O.N. de; OLIVEIRA, W.S.J. de; GARRIDO, M. da S.; AZEVEDO, R.L. de. Avaliação de cultivares de bananeira no Recôncavo Baiano. Ciência e Agrotecnologia, v.29, p.515-520, 2005. DOI: 10.1590/ S1413-70542005000300002.

LOPES, R.; BRUCKNER, C.H.; CRUZ, C.D.; LOPES, M.T.G.; FREITAS, G.B. de. Repetibilidade de características do fruto da aceroleira. Pesquisa Agropecuária Brasileira, v.36, p.507-513, 2001. DOI: 10.1590/S0100-204X2001000300015.

MANFIO, C.E.; MOTOIKE, S.Y.; SANTOS, C.E.M. dos; PIMENTEL, L.D.; QUEIROZ, V. de; SATO, A.Y. Repetibilidade em características biométricas do fruto de macaúba. Ciência Rural, v.41, p.70-76, 2011. DOI: 10.1590/ S0103-84782011000100012.

MANSOUR, H.; NORDHEIM, E.V.; RUTLEDGE, J.J. Estimators of repeatability. Theoretical and Applied Genetics, v.60, p.151-156, 1981. DOI: 10.1007/BF00264520.

MATSUO, É.; SEDIYAMA, T.; CRUZ, C.D.; OLIVEIRA, R. de C.T. Análise da repetibilidade em alguns descritores morfológicos para soja. Ciência Rural, v.42, p.189-196, 2012. DOI: 10.1590/ S0103-84782012000200001.

NEGREIROS, J.R. da S.; ANDRADE NETO, R. de C.; MIQUELONI, D.P.; LESSA, L.S. Estimativa de repetibilidade para caracteres de qualidade de frutos de laranjeira-doce. Pesquisa Agropecuária Brasileira, v.49, p.40-48, 2014. DOI: 10.1590/ S0100-204X2014000100006.

NEGREIROS, J.R. da S.; SARAIVA, L.L.; OLIVEIRA, T.K. de; ÁLVARES, V. de S.; RONCATTO, G. Estimativas de repetibilidade de caracteres de produção em laranjeiras-doces no Acre. Pesquisa Agropecuária Brasileira, v.43, p.1763-1768, 2008. DOI: 10.1590/ S0100-204X2008001200017.

OLIVEIRA, M. do S.P. de; MOURA, E.F. Repetibilidade de número mínimo de medições para caracteres de cacho de bacabi (Oenocarpus mapora). Revista Brasileira de Fruticultura, v.32, p.1173-1179, 2010. DOI: 10.1590/ S0100-29452010005000120.

OLIVEIRA, T.K. de; LESSA, L.S.; SILVA, S. de O. e; OLIVEIRA, J.P. de. Características agronômicas de genótipos de bananeira em três ciclos de produção em Rio Branco, AC. Pesquisa Agropecuária Brasileira, v.43, p.1003-1010, 2008. DOI: 10.1590/ S0100-204X2008000800008.

PADILHA, N.C.C.; OLIVEIRA, M. do S.P. de; MOTA, M.G. da C. Estimativa da repetibilidade em caracteres morfológicos e de produção de palmito em pupunheira (Bactris gasipaes Kunth). Revista Árvore, v.27, p.435-442, 2003. DOI: 10.1590/ S0100-67622003000400003.

RESENDE, M.D.V. de. Genética biométrica e estatística no melhoramento de plantas perenes. 21.ed. Brasília: Embrapa Informação Tecnológica; Colombo: Embrapa Florestas, 2002. $975 \mathrm{p}$.

RODRIGUES, M.G.F.; NACIF, P.G.F.; COSTA, O.V.; OLSZEVSKI, N. Solos e suas relações com as paisagens naturais no município de Cruz das Almas - BA. Revista de Biologia e Ciências da Terra, v.9, p.193-205, 2009. 
RUTLEDGE, J.J. A scaling which removes bias of Abeywardena's estimator of repeatability. Journal of Genetics, v.61, p.247-250, 1974. DOI: 10.1007/BF02986435.

SHIMOYA, A.; PEREIRA, A.V.; FERREIRA, R. de P.; CRUZ, C.D.; CARNEIRO, P.C.S. Repetibilidade de características forrageiras do capim-elefante. Scientia Agricola, v.59, p.227-234, 2002. DOI: $10.1590 /$ S0103-90162002000200004.

SILVA, S. de O. e; CARVALHO, P.C.L. de; SHEPHERD, K.; ALVES, E.J.; OLIVEIRA, C.A.P. de; CARVALHO, J.A.B.S. Catálogo de germoplasma de bananeira (Musa spp.). Cruz das Almas: Embrapa-CNPMF, 1999. 152p. (Embrapa-CNPMF. Documentos, 90).

SILVA, S. de O. e; FLORES, J.C. de O.; LIMA NETO, F.P. Avaliação de cultivares e híbridos de bananeira em quatro ciclos de produção. Pesquisa Agropecuária Brasileira, v.37, p.1567-1574, 2002. DOI: 10.1590/S0100-204X2002001100007.
SILVA, S. de O. e; MATOS A.P. de; CORDEIRO, Z.J.M.; LIMA, M.J.C.; AMORIM, E.P. Avaliação de genótipos tetraploides de bananeira cultivados em área infestada pelo agente causal do mal-do-panamá. Revista Brasileira de Fruticultura, v.33, p.125-132, 2011. DOI: 10.1590/S0100-29452011005000029.

SILVA, S. de O. e; PIRES, E.T.; PESTANA, R.K.N.; ALVES, J. da S.; SILVEIRA, D. de C. Avaliação de clones de banana Cavendish. Ciência e Agrotecnologia, v.30, p.832-837, 2006. DOI: 10.1590/ S1413-70542006000500002.

VASCONCELLOS, M.E. da C.; GONÇALVES, P. de S.; PAIVA, J.R. de; VALOIS, A.C.C. Métodos de estimação do coeficiente de repetibilidade no melhoramento da seringueira. Pesquisa Agropecuária Brasileira, v.20, p.433-437, 1985.

VENCOVSKY, R. Princípios de genética quantitativa. Piracicaba: Esalq, 1973. 97p.

Recebido em 7 de novembro de 2013 e aprovado em 31 de janeiro de 2014 